\title{
Research on Dynamic Compensation Achievement Path of Project Re-measurement based on Legal Fact Construction
}

\section{for State of Contract}

\author{
Yinyilin ${ }^{1, a}$, Yang xuan ${ }^{2, b}$ \\ ${ }^{1}$ School of Management Tianjin University of Technology, Tianjin, 300384, China \\ ${ }^{2}$ School of Management Tianjin University of Technology, Tianjin, 300384, China \\ a450241443@qq.com, byangxuan_eric@126.com
}

\begin{abstract}
Keywords: Re-measurement, State of Contract, DynamicCompensation, Legal Fact
Abstract.Currently, the disputes on re-measurement and payment of the project cost between the employers and contractors in the projects istypicallyphenomenon. Such situation can be caused by the interference factors in the contract execution process, which can break the balance of the original state when the contract is signed but the employers cannot implement the effective compensation for the contract change state of the contractor. Perspective of the based on the presumption on the legal fact, the reasoning deduction method is used to convert the objective facts to be the directory application of the legal facts, which is further used to pay the bill of quantities and analyze the construction elements and construction path in the payment of bill of quantities.
\end{abstract}

\section{Introduction}

The dispute on the project amounts between the employers and contractors accounts for considerable proportion in dispute cases on construction project cost heard by people's court. Such situation can be caused by the interference factors in the contract execution process, which can break the balance of the original state when the contract is signed but the employers cannot implement the effective compensation for the contract change state of the contractor. Research is indicated that employers can implement the compensation for the contract state at any time byprojectre-measurement in unit price contract in project amounts list valuation model, which is dynamic compensation. Re-measurement and payment is closely related to project construction and project cost and go through the whole construction process. Yet there has not research on how to convert project re-measurement results into project cost settlement basis from the perspective of presumption based on the legal fact. Therefore, it is essential to explore the presentation pattern of project re-measurement as compensation mode of the contract change state thus to regulate legal procedure of project re-measurement condition.

\section{Lite rature review}

Analysis for project re-measure ment's realizing dynamic compensation for contract state

According to the regulation on project re-measurement in Construction Project Amounts List Valuation Norms（GB50500-2013）, Standard Construction Tender Documents (No.56 of Order of Nine Ministries), project calculation is to confirm and calculate project amounts actually finished by contractors according to calculation rules and method regulated in the contract and is an important basis of progress payment paid by employers to contractors. Project calculation result is the basis and foundation of state compensation in case of contract state change. In the practical project 
settlement, employers often take completion drawing as basis and deny the legal project amounts established during re-measurement and payment for previous times that the results of many project amounts cannot be state compensation basis. Wang Jinglong points out complying the re-measurement with rules and regulation is priority for contract management, otherwise, the actual project amounts could not be measured to employers. Wu Qiuli, et al think that the difference of project amounts confirmed by contractees and contractors is caused by inconsistent measurement basis and standard of two parties, because re-measurement results do not form legal fact, meaning legal project amounts. So, research is required for the construction path on how to transfer objective fact into legal fact.

\section{Inte raction relationship between objective fact and legal fact}

Objective fact refers to the actual situation of the matter, emphasizing its truth. Legal fact means the fact inducing legal relationship and it needs to be proved with rule of evidence and tried and judged by judge according to procedure. Legal fact is the phenomenon regulated in the law which can lead to generation, alternation and extinction of legal relation and one of its main characteristics is to compulsorily comply with the assumption in the normative logic structure in the law. Objective fact is not a legal concept and it refers to all facts in objective existence. It has no legality, state will and equality characterized by legal fact. So, not all objective facts can become legal fact for the objective fact is basis of legal fact while legal fact is reflection and reproduction of objective fact. The affirmation and decision for legal fact is explained according to Procedural Law while evidence is the key of legal fact finding. Evidence comes from objective fact to prove its occurrence and it is also the basis for the judge to identity legal fact and infer the truth of objective fact, so, the evidence materials submitted in the process of objective fact becoming legal fact play the link roleand are also critical for the consistence between objective fact and legal fact. The presumption for the consistence between objective fact and legal fact is shown in Fig. 1.

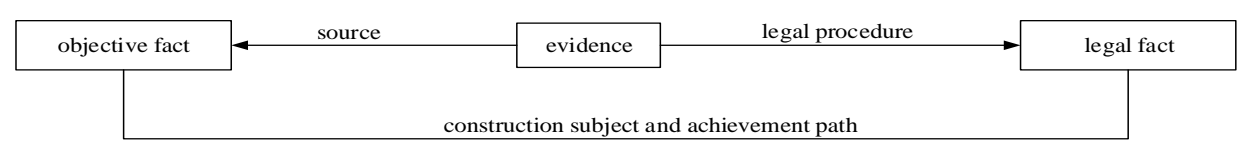

Fig. 1 Consistence path of objective fact and legal fact

After the contract is concluded by contractees and contractors, employers and contractors become combination in contractual relationship during contract performance. After contractors perform obligations according to regulation in the contract, employers have the responsibility to perform obligation and contractors are obliged to assert a claim, namely employers have payment responsibility and contractors have the right to ask for payment. So, each payment act of employers is performance for the debt and the accomplishment of the last payment act means the extinction of debt relationship between contractees and contractors. The procedural documents confirmed by both parties in project measurement and payment become important condition for legal fact-finding.

\section{Construction factor analysis of legal fact in project re- measurement and payment}

\section{Objective fact in project re-measurement and payment}

Contract price is often adjusted during project construction process. The occurrence of those adjusted matter is belonged to objective fact and it is actual fact originally occurred and existed ind ependent of people's subjective consciousness. However, the occurred objective fact cannot lead to production, alternation and extinction of legal relation until being transferred into legal fact. The court identities truth of the case mainly according to legal fact and the top task for judicial officials in lawsuit process is to properly transfer objective fact of the case into legal fact by collecting, judging and examining evidence to guarantee consistence between objective fact and legal fact to 
the furthest extent. Currently, contract price adjustment is regulated in the law, regulation, contract sample and project amounts list valuation norm respectively. Objective fact and legal fact in project re-measurement and payment are discussed taking three contract samples including Standard Construction Bidding Document(2007), Construction Contract(2013 official version) and FIDIC's Condition of Contract for Construction Version 1999, Temporary Method of Construction Project Price Settlement(No. 369 of Document)and Construction Project Amounts List Valuation Norms Version 2013(as shown in Fig. 2).

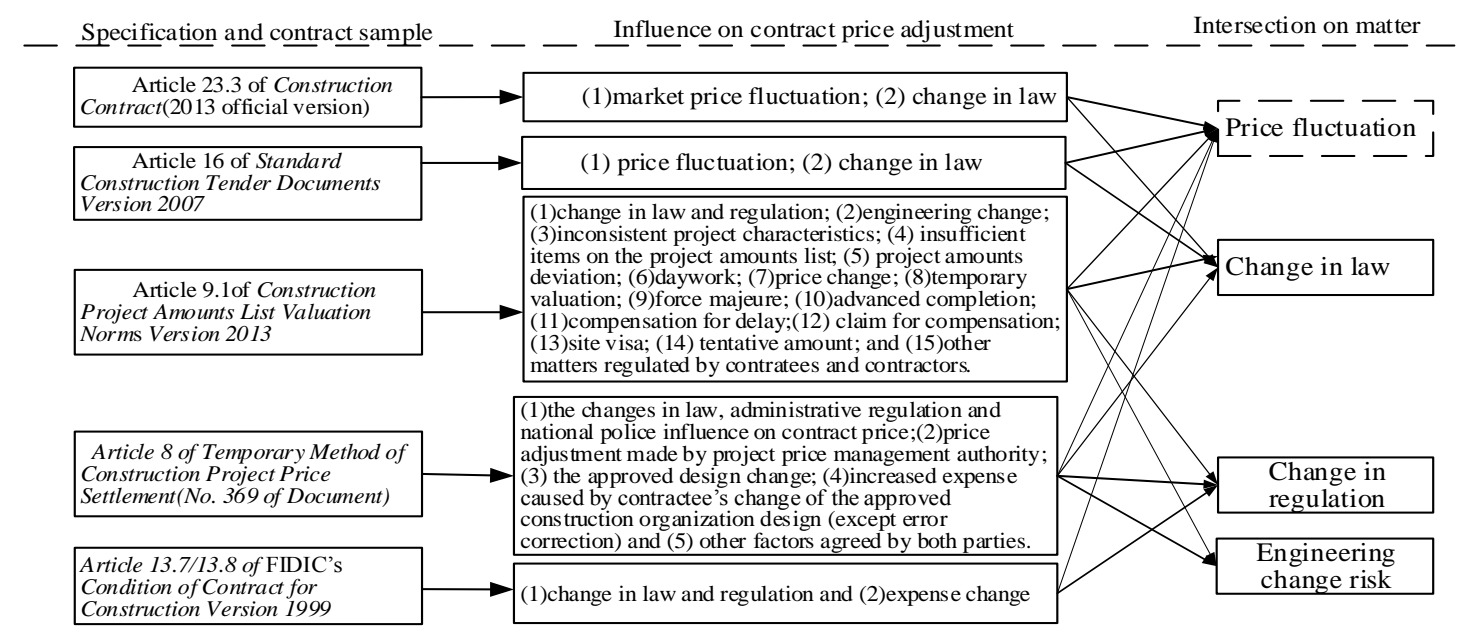

Fig. 2 Relevant regulations on contract price adjustment in specification and contract samples

It is found from summary of the above content that the adjustment items on contract price are concentrated on price fluctuation, change in law and engineering change although there are different regulations in the law and regulation, contract sample and project amounts list norm. Price fluctuation, change in law and engineering change belong to objective fact, however, price fluctuation risk is undertaken by contractees and contractors; change in law generally has no direct influence on increase or decrease of project amounts and engineering change is the major item to influence on project amounts and its risk is undertaken completely by employers. Therefore, for increase or decrease of project amounts caused by engineering change, it needs to transfer objective fact into legal fact by regulating and perfecting measurement procedure.

\section{Legal fact in project re-measure ment and payment}

Engineering change is confirmed in the forms of engineering changenotice, work communication form of engineering change, site visa and daywork table, etc, which are evidence to transfer engineering change into legal fact. After confirmed by three parties including employers , contractors and engineers, the evidence is deemed to be legal fact that is in compliance with legal procedure and becomes payment basis for project cost.

\section{(1)Engineering change notice/work communication form}

Engineering change notice is generally issued by design about alternation, improvement or optimization of the original construction drawing and designed documents. Work communication form of engineering change is issued by employers and the change reasons need to be written in detail, including change reason, items to be changed, implementation measure and estimated project cost, etc. After approved by supervision unit, it needs to report to employers for approval. The form is included in the contract.

\section{(2) Site visa}

There are many kinds of site visa. The letters on evidence of responsible event between contractees and contractors in project implementation could become site visa. Not all visa can calculate price immediately and some visa needs to go through claim procedure. Then visa is only 
the basis of claim for compensation and some visa does not involve price at all but evidence of certain event. So visa is the matter to cause contract price adjustment and also confirmation procedure for the matter of contract price adjustment.

(3) Daywork table

For some additional odd work occurred in project implementation process, contractors should execute if contractees notice contractors to implement in daywork way. Contractees should deliver change order in written form and provide necessary materials. It is convenient for settlement to implement odd project beyond contract in daywork way. Generally, the odd work is paid by "tentative amount"listed in other item list. The unit price is determined by daywork reported by contractors in daywork table and the project cost is changed according to actually accomplished project amount. In the practice, when the occurred change is small work, it is valuated in daywork way and according to daywork unit price in project amounts list after decomposing the work and estimating manpower, materials and consumed machine-team quantity.

\section{Construction path analysis for legal fact in project re-measurement and payment}

\section{Project re-measurement and payment evidence}

Legitimate inference and affirmation is made for truth of case after cross-examination and trust of legal fact in legal procedure according to evidence rule and evidence materials submitted by the party. It is observed that the path to guarantee consistence between legal fact and objective fact in project re-measurement and payment has gone through a series of legal measurement and payment procedure.

Project re-measurement is measured according to regulated measuring rules and actual project accomplishment and paid in the way, procedure and term agreed in the contract. Project amounts are multiple. At project transaction stage, pricing engineer calculates project amounts on the drawing according to uniformed measuring rules based on the design drawing and the project amounts are the amounts used by contractor in bidding. The project amounts in this list are only tentative when unit price contract is adopted.

\section{Legal procedure of project re-measurement and payment}

\section{(1) Contractors submit the finis hed project amounts table}

Contractors measure the finished project and submit progress payment application, finished project amounts reports and relevant measurement materials. The settled project amounts in the finished project amounts reports are the project amounts actually accomplished by contractors and measured according to the measurement method regulated in the contract.

\section{(2) Supervisors review the finished project amounts in unit price contract}

After contractors finish project amounts of each subtitle in project amounts list in unit price subtitle, supervisor should ask contractors to send representatives to jointly make summary of all previous measurement reports under each subtitle to verify finial settled project amount. Supervisors may ask contractors to provide supplementary measurement materials thus to confirm the accurate project amounts for the last process payment. If contractors do not sent representatives to participate in the work according to supervisors'requirement, the project amounts verified by supervisors is deemed as the accurate project amounts under the subtitle finished by contractors.

Supervisors review the finished project amounts reports submitted by contractors to confirm the actually accomplished project amount. If doubting about the quantity, supervisors could ask contractors to join in the review and draw sample for re-measurement according to regulation in the contract. Contractors should assist supervisors for review and supply supplementary measurement materials according to supervisors' requirement. If contractors do not participate in review 
according to supervisors' requirement, the project amounts reviewed or corrected by supervisors is deemed to be the project amounts actually finished by contractors.

\section{(3)Handling measurement results in doubt}

If contractees doubt about quantity of the finished project amounts under unit price subtitle, both contractees and contractors review and draw a sample for re-measurement according to project re-measurement method regulated in the contract. If contractors think the measurement results wrong after contractees'varification, they can provide written advice within seven days after receiving measurement results and annex their correct measurement results and detailed calculation materials. After receiving the written advice, contractees should notice contractors within seven days after reviewing contractors'measurement result. If contractors still doubt about reviewed measurement results, dispute is handled in the method regulated in the contract.

\section{Achievement research of legal fact construction in project re-measurement and payment}

\section{Project re-measurement and payment based on Construction Project Amounts List Valuation Norms Ve rsion 2013}

It is regulated in Construction Project Amounts List Valuation Norms(GB50500-2013) that all previous project re-measurement results are listed in settlement, emphasizing effectiveness of measurement results and all previous payment during the process are directly summarized to enter into settlement materials which simplifies settlement process and avoid repeated calculation of project amount. It is required that the project re-measurement results and contract price confirmed during the process directly enter into settlement, emphasizing importance of meas urement results during the process. To ensure accuracy of measurement results during contract performing stage, feedback mechanism is provided according to engineering control principle and it is 1)a correcting program for all previous payment certificate; and 2) project amounts payment program.

According to Construction Project Amounts List Valuation Norms(GB50500-2013), project re-measurement payment evidence in unit price contract is mainly including progress payment certificate, site visa and daywork table, etc and besides daywork table, the process documents are also contained in lump-sum contract including decomposed tables of progress payment for the total price project. Once confirmed by employers, supervision engineer and contractors, these evidence become progress documents with legal effect, transferring objective fact into legal fact.

Project re-measurement legal procedure based on Construction Project Amounts List Valuation Norms Ve rsion 2013

Project amounts must be calculated according to project amounts calculation rules regulated in current national measurement specification on relevant projects. Project re-measurement can be measured in sections according to monthly or progress image and the specific measurement period is regulated in the contract. The project amounts constructed or reworked beyond project scope in the contract caused by contractors is not measured by contractees. The cost-and-premium contract is measured according to measuring rules of unit price contract.

Project amounts in unit price contract must be the confirmed project amounts which is the measured project in the contract finished by contractors and calculated according to according to project amounts calculation rules regulated in current national measurement specification. Project re-measurement under construction is calculated according to accomplished project amounts by contractors in performing obligations in the contract, if it is found insufficient items in bidding project amounts list, project amounts deviation or project amounts increase/decrease resulting from engineering change. The specific measurement procedure is as below: 


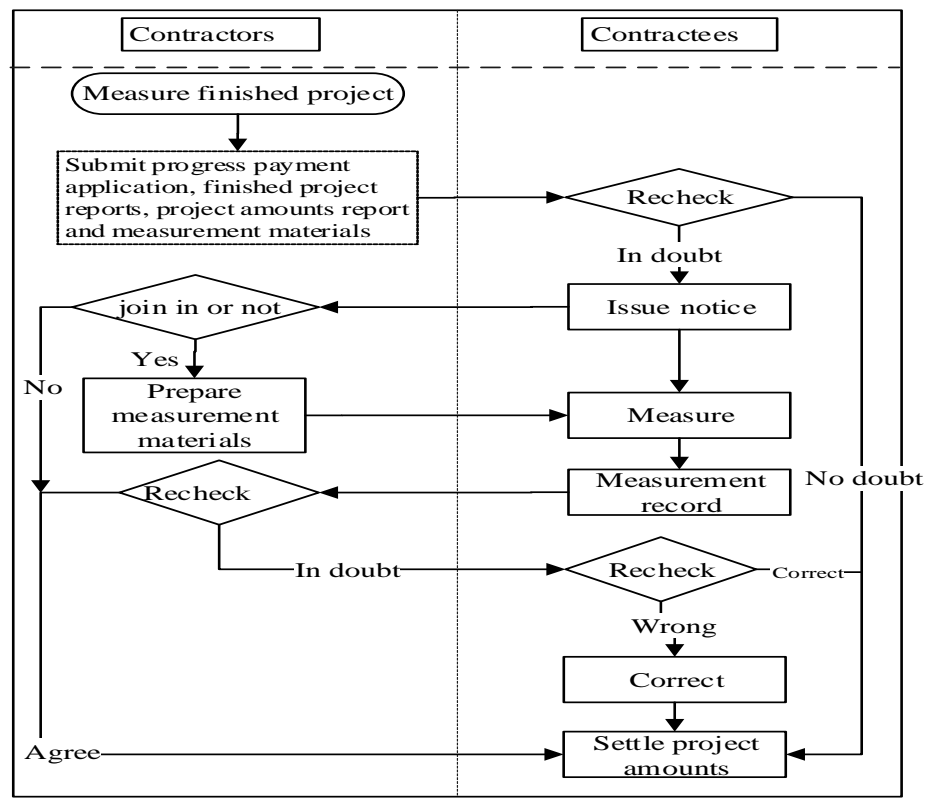

Fig. 3 Project re-measurement procedure

\section{Conclusions}

The key for objective fact to become legal fact is in accordance with "legal procedure" to make reasonable affirmation on fact according to "evidence rule". The objective fact in project re-measurement and payment is engineering change and other items and the evidence to transfer engineering change into legal fact is including work communication form of engineering change, engineering change notice, site visa and daywork table, etc. These evidence becomes legal fact once confirmed by employer, contractors and supervision engineers. On the whole, evidence in project re-measurement and payment is progress document like progress payment certificate in the implementation of contract. The progress payment certificate is formed through legal procedure and its issuance is approved by employers, contractors and supervision engineers. The project re-measurement results during the course of progress payment is effective and also verify the conclusion that project re-measurement result confirmed by contractees and contractors in construction process of contractual project directly enter into settlement in handling completion settlement. The path of project re-measurement presumed based on legal fact dynamically compensating state of contract provides a new idea to solve dispute of project re-measurement and payment and provides reference to standardize price payment act and reduce payment settlement dispute.

\section{References}

[1]Yang Jingxin. Discussion on Construction Project Price Dispute [J].Beijing Arbitration,2010(4):36-48.

[2] Li Xiaolong, Zhang Shuyi \& Wang Libin. Research on State of Contract and its Change Control Model of Project[J].Journal of Tongi University, 2006(4):563-568.

[3] Yin Yilin, Wang Jianyun \& Guo Kaiyin. Application Research on State of Contract Analysis in Claim Management[J]Journal of Shenyang Jianzhu University(Social Science edition), 2011(7):299-302.

[4] Sun Changzeng. Research on Project Price Payment and Settlement Control on Employers Party[D].Tianjin University of Technology, 2010.

[5] Shi Fusheng. Discussion on Project Settlement Review based on Project amounts List [J].Science and Technology Innovation Herald, 2009(2):171. 
[6] Yin Yilin, An Jiaojiao \& Zhang Yiyuan. Research on Improvement of Project Settlement Way based on Contract Management Concept[J]. China Harbour Engineering.2013(3):87-92.

[7] Wang Jinglong. Discussion on Project Re-measurement in Contract Management[J].Shanxi Architecture,2005(2):136-137.

[8] Wu Qiuli, Wei Yanbin, Zhao Yan \& Zhou Lili. Research on Application of Project Re-measurement Management System in Pipeline Project[J].Electronic Instrumentation Customers,2013(2):67-72.

[9] Yang Jianjun. Legal Fact Concept[J]. Science of Law(Northwest University of Political \& Law), 2004(6):43-52.

[10] Xiao Hongxia. Research on Missing Items in Construction Project Budget(Settlement) Statement[J]. Supervision Test and Cost of Construction.2011(6):45-47.

[11] Huang Hongsheng. Relationship and Significance between Objective Fact and Legal Fact[J]. Fujian Tribune (The Humanities \& Social Sciences), 2007(7):139-141.

[12] Yan Cunsheng \& Wang Haishan. Legal Philosophy Thought of the Concept of "Legal Fact" [J]. Legal Forum,2002,17(1):5-12.

[13] Sui Pengsheng. New Exploration for Establishment of Contractual Legal Relationship-Theory Analysis Starting from "Legal Fact" [J]. Political Science and Law. 2012(7):116-124.

[14] Kong Xiangjun. View on Legal Fact and Objective Fact[J]. Tribune of Political Science and Law(Journal of China University of Political Science and Law),2002,20(5):86-99.

[15] Li Lifeng. View on the Principle of "Based on Facts" [J]. Journal of China Youth University for Political Sciences,2002,21(3):123-125.

[16] Sun Guoqiang \& Bailin. From “Objective Truth" to "Legal Truth"-Discussion on Standard Transition of Criminal Justice in O ur Country [J]. Journal of Guangxi University (Philosophy and Social Science) ,2011,33(4):78-81.

[17] Chen Guangzhong. Study on Several Theory and Practice Problems of Criminal Evidence System Reform-from the Perspective of Three Volumes of Two Evidence Regulations Published by Chinese Academy of Science and Chinese Academy of Engineering [J]. China Legal Science,2010(6):5-16.

[18] Zhang Xiaoli. Research on Achievement Path of Construction Contract Price Adjustment from the Perspective of Risk Sharing[D]. Tianjin: Tianjin University of Technology, 2013. 